Check for updates

Cite this: RSC Adv., 2018, 8, 30289

\title{
Design of a scalable AuNP catalyst system for plasmon-driven photocatalysis $\uparrow$
}

\author{
Heike Lisa Kerstin Stephanie Stolle, (D) *ab Frank Garwe, ${ }^{a}$ Robert Müller, ${ }^{a}$ \\ Thomas Krech, ${ }^{\mathrm{C}}$ Bastian Oberleiter, ${ }^{\mathrm{d}}$ Thomas Rainer, ${ }^{\mathrm{d}}$ Wolfgang Fritzsche ${ }^{\mathrm{a}}$ \\ and Achim Stolle ${ }^{b}$
}

\begin{abstract}
In this work we present a simple, fast and cost-efficient synthesis of a metal nanoparticle catalyst on a glass support for plasmon driven heterogeneous photocatalysis. It is based on efficient mixing of metal salts as particle precursors with porous glass as the supporting material in a mixer ball mill, and the subsequent realization of a complete catalyst system by laser sintering the obtained powder on a glass plate as the support. By this, we could obtain catalyst systems with a high particle proportion and an even spatial particle distribution in a rapid process, which could be applied to various kinds of metal salt resulting in plasmon active metal nanoparticles. Furthermore, the catalyst production process presented here is easily scalable to any size of area that is to be coated. Finally, we demonstrate the catalytic performance of our catalysts by a model reaction of ethanol degradation in a self-designed lab-scale reactor.
\end{abstract}

Received 28th April 2018

Accepted 10th August 2018

DOI: $10.1039 / \mathrm{c} 8 \mathrm{ra03661f}$

rsc.li/rsc-advances

restoring force of the positively charged nuclei, can be excited

\section{Introduction}

Plasmon active noble metal nanoparticles like silver, gold, platinum or palladium find applications in many fields of research, e.g. in bioanalytical sensing, ${ }^{1-3}$ surface enhanced Raman spectroscopy (SERS) ${ }^{4,5}$ and in catalysis. ${ }^{6-11}$ The synthesis of such particles is possible, in different shapes and sizes, using noble metal salts. Like this, gold nanoparticles have been synthesized, e.g. as colloidal, quasi-spherical particles, ${ }^{12-15}$ nanorods ${ }^{16-18}$ nanocubes ${ }^{19,20}$ and nanostars. ${ }^{21}$ For silver nanoparticles, plenty of different shapes are also available, for instance spheres, ${ }^{22,23}$ nanocubes ${ }^{24,25}$ and prisms. ${ }^{26-28}$ However, platinum has mainly been synthesized in non-specific structures ${ }^{29}$ or as platinum cubes, ${ }^{30}$ which is similar for palladium nanoparticle synthesis. ${ }^{31-33}$

What makes these particles so interesting for applications is the so called localized surface plasmon resonance (LSPR) effect they show, which is characteristic of such particles. ${ }^{34}$ In this effect, the valence electrons in the metal, which - under the influence of light - are constantly oscillating against the

${ }^{a}$ Leibniz Institute of Photonic Technology (IPHT), Department of Nanobiophotonics, Albert-Einstein-Straße 9, D-07745 Jena, Germany.E-mail: Lisa.Stolle@leibniz-ipht.de ${ }^{b}$ Institute of Technical and Environmental Chemistry, Faculty of Chemistry and Earth Sciences, Friedrich-Schiller-University Jena, Philosophenweg 7A, D-07743 Jena, Germany

'JENOPTIK Automatisierungstechnik GmbH, Konrad-Zuse-Straße 9, D-07745 Jena, Germany

${ }^{d}$ HEGLA boraident GmbH \& Co. KG, Köthener Straße 33a, D-06118 Halle/Saale, Germany

$\dagger$ Electronic supplementary information (ESI) available. See DOI: $10.1039 / \mathrm{c} 8 \mathrm{ra03661f}$ by wavelengths resonant to this movement, resulting in a simultaneous oscillation of electrons (plasmon resonance). The wavelength of light necessary to initiate this process is different for each metal but also varies with shape and particle size of the same metal. ${ }^{34-36}$ By this effect, a strongly enhanced electric field is formed in the direct environment of a particle. This field enhancement can be around six times higher than the field intensity of irradiating photons for gold nanospheres ${ }^{37}$ and even up to $10^{3}$ times higher in the cases of other shapes..$^{35}$ The oscillation can be kept up for times in the fs and ps regions for electron-electron and electron-phonon relaxation, respectively. ${ }^{36,38}$ Decay is possible in different processes. Thus, the resonant light irradiated can be scattered, which is particularly the case for larger particles above $100 \mathrm{~nm},{ }^{35}$ or it can form carriers of energetic charge in the case of smaller particles. ${ }^{10}$ Energetic charge carriers can either relax and form heat at the nanoparticle surface, heating up components in their close environment (plasmonic heating), or they can result in electron-hole-pairs, ${ }^{10,38}$ meaning electrons can be donated to surrounding molecules or taken from them, with both of these initiating their degradation process. ${ }^{11,35,39}$

The abundance of possible mechanisms of converting light energy makes metal nanoparticles a desirable material for photocatalysts. ${ }^{39}$ Photocatalysts in general are becoming more popular, because classical catalysts which are activated with thermal energy require a high energy input, and in order to maintain the temperature for the highest turn-over a constant energy input is required. In the case of photocatalysis, this is not necessary, because in the best cases sunlight, which is abundantly available and makes any other energy sources 
redundant, can be used to drive reactions. ${ }^{34}$ Due to this, the catalysis becomes easily switchable by having a light on when energy is required to activate the catalyst, and having the light off when it is not. Gold nanoparticles are especially in demand for implementation as catalysts, as these particles exhibit a rich variety of shapes covering the absorption of almost the entire spectrum of visible light, ${ }^{35,40}$ and are also very stable. ${ }^{39}$ Regarding plasmon catalysis, this makes gold a very interesting catalyst material exploiting the energy of the VIS area of (sun) light. $^{34}$ But combining gold catalysts with particles of other metals like silver, ${ }^{41,42}$ palladium ${ }^{4-46}$ or platinum ${ }^{47}$ and semiconductors like $\mathrm{TiO}_{2}$ (ref. 48-50) is also possible. Such combinations open up new possibilities for plasmon catalysis, as these allow the tuning of the irradiation wavelength needed. ${ }^{\mathbf{4 1 , 4 2}}$

The synthesis of metal nanoparticles of different metals and in different shapes is nowadays state of the art, as described here. Bottom-up techniques range from classical wet-chemical synthesis $^{12-19,21-27,29-33}$ to microfluidic ${ }^{20,28}$ and photochemical syntheses $^{51}$ using metal salts as precursor materials, and to electrochemical synthesis approaches utilizing metal plates as electrodes. ${ }^{52}$ Classical top-down methods include lithographic approaches and laser ablation, where a metal plate in water is treated with a laser, resulting in monometallic particles, ${ }^{53}$ but the production of alloys ${ }^{54}$ or bimetallic particles ${ }^{55}$ is also possible. Problems regarding these techniques are, however, the low yields of particles as catalysts and the production costs, making them inappropriate for catalyst production and their upscaling. ${ }^{56}$

Another obstacle is making the particles usable for their application as catalysts. Here, more preparation steps are often required. In (quasi-)homogeneous catalysis, this problem is quite simple to overcome because the particles of the material to be used can stay in the solution where they were synthesized. Afterwards, the reactants are added (as solution) and the catalytic reaction is initiated by light of the required wavelength. This was done, for example, by utilizing Ag and Au nanospheres and AgAu-nanorings in solution to oxidize and degrade methylene blue. ${ }^{41}$ The case of heterogeneous catalysis (which represents the majority of catalytic applications) is not that simple, as the metal nanoparticles need to be immobilized on a supporting material. Here, mostly particles of different materials are used as a support and are coated with the plasmon active nanoparticles, and are utilized to feed packed bed reactors. ${ }^{6,10,57,58}$ This involves the use of $\mathrm{TiO}_{2}$ or $\mathrm{SiO}_{2}$ as supportive materials, as shown in the studies from Mukherjee et al. describing the dissociation of $\mathrm{H}_{2}$ mediated by plasmon heating of supported AuNPs prepared in a 3-step process. ${ }^{10,57}$ Rombi et al. present the oxidation of $\mathrm{CO}$ at AuNPs on $\mathrm{SiO}_{2}$, activated by 3-mercaptopropyltrimethoxysilane prior to loading with AuNPs by thermal reduction of a $\mathrm{HAuCl}_{4}$ solution in the presence of citrate. ${ }^{58}$ Studies from Christopher et al. demonstrated the use of $\alpha-\mathrm{Al}_{2} \mathrm{O}_{3}$ particles as a support for AgNPs for plasmon catalyzed oxidation reactions. ${ }^{6}$ In other systems, like the microfluidic reaction chamber reported by Adleman et al. used for the plasmon-assisted catalysis of ethanol and water in the liquid phase, a catalyst system consisting of gold nanoparticles spincoated onto a glass object slide was used. ${ }^{8}$ Hou et al. describe a similar system for gas phase conversion of $\mathrm{CO}_{2}$ to hydrocarbons over $\mathrm{TiO}_{2}, \mathrm{AuNP} / \mathrm{TiO}_{2}$ or pure AuNP catalysts on a glass support, where gold was introduced by electron beam evaporation. ${ }^{59}$

The preparation of plasmon-based catalyst systems described so far in the literature is usually based on several working steps, consuming time and also resources, especially regarding the metal precursor salts. Usually the systems described are laid out for classical packed bed reactors and are difficult to scale-up or scale-down for smaller reactor systems. In the present paper, we introduce a new method to design a complete catalyst system consisting of plasmon active nanoparticles on a glass support. In the process, we were able to obtain integrated AuNP catalysts. Therefore, the methodology is very easy and fast to carry out, is cost-efficient regarding the metal precursors used, and is scalable to different sizes of supporting glass plates. This catalyst is intended for use in packed bed reactors with bypass flow, allowing thorough irradiation of the catalyst in comparison to classical packed bed reactors. In total, only two steps are necessary for the catalyst production: the first being the grinding of the metal precursor material $\mathrm{HAuCl}_{4}$ with porous glass, and the second being the laser sintering of the obtained metal precursor/glass mixture on the desired glass plate support, resulting in spherical metal nanoparticles. The process was preliminarily tested for small object slides (coated area $60 \times 20 \mathrm{~mm}$ ), but could be also demonstrated on glass plates of $100 \times 100 \mathrm{~mm}$. Finally, the catalytic performance of the realized catalyst systems was evaluated by degradation experiments of ethanol in a self-designed testing plant and a bypass-flow photoreactor.

\section{Experimental section}

\subsection{Chemicals and materials}

Ethanol and $\mathrm{HAuCl}_{4}$-trihydrate $(49.5 \% \mathrm{Au}$ content) were obtained commercially from Alfa Aesar, Karlsruhe, Germany and were used without further purification. Porous glass with different pore sizes was delivered by HEGLA boraident (Halle/ Saale, Germany). Glass samples with initial pore sizes of 1$2 \mathrm{~nm}, 50$ and $100 \mathrm{~nm}$ were delivered in larger pieces, whereas 200 and $370 \mathrm{~nm}$ glass samples were obtained preground. As a support material for the coating, Schott BOROFLOAT ${ }^{\circledR}$ plates with a size of $150 \times 150 \times 1 \mathrm{~mm}$ obtained from HEGLA boraident (Halle/Saale, Germany) were used.

\subsection{Mixing of $\mathrm{HAuCl}_{4}$ with porous glass}

For the mixing of the particle precursor, $1 \mathrm{~g}$ of porous glass was put into a $35 \mathrm{~mL} \mathrm{ZrO}_{2}$-milling beaker and $20 \mathrm{mg}$ of $\mathrm{HAuCl}_{4}$ was added, in order to obtain in total a $1 \mathrm{wt} \%$ distribution of metal to glass. Through two slots for milling beakers, the second milling beaker was filled only with porous glass for comparison of the resulting powders. Then, $25 \mathrm{~g}$ of $5 \mathrm{~mm} \mathrm{ZrO}_{2}$ milling balls was added to each beaker and the grinding process was carried out at $30 \mathrm{~Hz}$ for $60 \mathrm{~min}$ with a mixer ball mill Retsch 400M. 


\subsection{Characterization of ground mixtures}

The grinding mixtures were evaluated by particle size distribution measurements (PSD-measurements by dynamic light scattering, DLS) with a Fritsch Analysette 22 with a wet dispersion unit. Each measurement was carried out with ultrasound. Measurements for the analysis of BET surface areas and total pore volumes were done with a Quantachrome Autosorb iQ3 system. All ten samples (79.5-110.0 mg) were degassed for $1.2 \mathrm{~h}$ at temperatures up to $150{ }^{\circ} \mathrm{C}$ before nitrogen adsorption measurements were carried out at $77.35 \mathrm{~K}$. For all of the samples, complete adsorption/desorption isotherms were measured. SEM imaging was carried out with a field emission scanning electron microscope, FE-SEM JSM 6300F, JEOL, in BSE contrast after sputtering the samples with graphite. Light microscopy was done with a Zeiss Axio Imager.A1m with Axio Cam MRc5 device.

\subsection{Laser sintering of obtained mixtures on supporting glass plates}

The comminuted mixtures were dispersed in ethanol and homogenized in an ultrasonic bath. Afterwards, the mixture was applied homogeneously onto a $76 \times 26 \mathrm{~mm}$ object slide in an area of $60 \times 20 \mathrm{~mm}$, and onto $150 \times 150 \mathrm{~mm}$ float glass plates in a square of $100 \times 100 \mathrm{~mm}$ in the middle of the plates and the ethanol was evaporated under IR radiation. Then, the material was laser sintered with a $\mathrm{CO}_{2}$-laser under mild conditions in a cross-hatch, so that the glass/metal precursor mixture was just superficially sintered. The laser feed rate was $40 \mathrm{~mm} \mathrm{~s}^{-1}$ and the line distance was $150 \mu \mathrm{m}$. The laser power was $0.85 \mathrm{~W}$.

UV/VIS measurements of the catalysts on supports were conducted using an Ulbricht sphere with a Perkin Elmer Lambda 900 UV/VIS/NIR Spectrometer. XRD measurements were made with an X'PERT MPD Pro (PANalytical) system using $\mathrm{Cu}$ K-alpha-radiation $(\lambda=0.154 \mathrm{~nm})$. The crystallite size $L$ was calculated according to the Scherrer equation. Raman measurements were carried out using a confocal WITec Raman Microscope alpha300 R setup with a water immersion objective from Nikon with $10 \times$ magnification and a numerical aperture (NA) of 0.25 . The excitation wavelength was $785 \mathrm{~nm}$ by a cw diode laser from Toptica Photonics. Grating was set to 300 grooves per $\mathrm{mm}$ and the integration times were $2 \mathrm{~s}$ for the pure sample before and after catalysis, and $5 \mathrm{~s}$ for the sample with ethanol.

\subsection{Catalytic tests}

Catalytic tests were carried out in a self-constructed testing plant made of Swagelok® stainless-steel tubes, a temperaturecontrolled glass saturator and a self-designed bypass-flowphotoreactor. The glass saturator with ethanol was tempered to $273 \mathrm{~K}$ by an IKA RC2 Basic thermostat in order to evaporate the alcohol as the component to be degraded. A mass flow controller for nitrogen (Brooks GF series) with a control unit

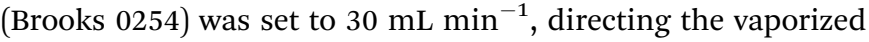
ethanol towards the reactor. Before reaching the reactor, another mass flow controller for air was set to $300 \mathrm{~mL} \mathrm{~min}^{-1}$.
The pressure of the gas mixture is controlled by a pressure gauge (Keller LEO 2) before and after passing the reactor. Plasmonic catalysis is initiated by irradiation with a Xe arc lamp (LSB530A, obtained from LOT-QuantumDesign $\mathrm{GmbH}$ ) with a spectral range of $200-900 \mathrm{~nm}$ in a LOT Oriel LSH201 housing and control unit. The reaction is monitored with the help of an Agilent gas chromatograph 7890B equipped with a flame ionization detector (FID) and a thermal conductivity detector (TCD). A PoraPLOT Q $(25 \mathrm{~m}, 320 \mu \mathrm{m}, 10 \mu \mathrm{m})$ was used as the column. The GC was calibrated with different amounts of ethanol in the gas phase and the ethanol concentration was calculated from the peak areas of ethanol. For calculations, a saturated vapor pressure of ethanol at 273.15 K of $1568 \mathrm{~Pa}$ (Dortmund Database, DDBST) was used. The measured pressure in the testing plant was $102000 \mathrm{~Pa}$ before and after the reactor chamber. The retention time of $\mathrm{CO}_{2}$ was verified by the injection of pure $\mathrm{CO}_{2}$.

The calculations of percentual ethanol degradation $/ \mathrm{CO}_{2}$ increase are based on the average peak areas measured without light (except outliers) and the respective value measured after the light was switched on. Here, a range of strong ethanol degradation was measured before reaching steady-state conditions. For comparison, the average value of the latter was used.

\section{Results and discussion}

\subsection{Analysis of grinding mixtures}

The mixtures obtained from the grinding process - without and with $\mathrm{HAuCl}_{4}$ - are displayed in Fig. 1, left. A change in color can be seen for the sample containing the gold precursor, exhibiting a purple to violet color. This color points to an initial formation of particles already in the grinding step, as mixtures containing only the precursors are expected to be yellow arising from the colour of $\mathrm{HAuCl}_{4}$. SEM images (Fig. 1, right) confirm this assumption, but also show that this happens only occasionally and most of the material is still present as the glass/metal salt bulk. Data for particle size analyses and nitrogen adsorption measurements of the porous glasses with and without addition of $\mathrm{HAuCl}_{4}$ can be found in the ESI (Tables $\mathrm{S} 1$ and $\mathrm{S} 2 \uparrow$ respectively).

\subsection{Analysis of complete catalyst plates}

The formation of metal nanoparticles through laser irradiation without reducing agents present was demonstrated in the literature for AuNPs from $\mathrm{HAuCl}_{4}$ in solution. ${ }^{60}$ However, for the utilized glass support, tests needed to be done in order to evaluate whether it is possible to obtain a stable and regular coating with nanoparticles through laser impact on mixtures of glass powder and $\mathrm{HAuCl}_{4}$. Therefore, pretests on object slides were done in areas of $20 \times 60 \mathrm{~mm}$. The obtained coated glasses exhibit a strong red to deep wine red colour comparable to the powder obtained by grinding, indicating the formation of gold nanoparticles. Also, it can be seen in both cases that the coating is regular, which indicates a uniform coating with the nanoparticles (Fig. 2).

The localization of the catalyst particles on the glass surface is crucial for catalytic applications, in order to enable light activation and to be accessible for the reactants in order to 

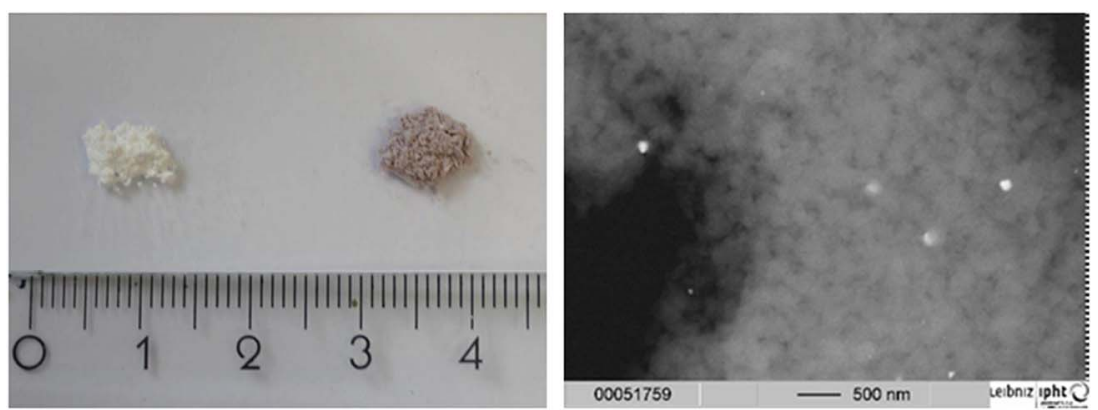

Fig. 1 Left: Photo of samples ground with no metal salt (white powder), and with $\mathrm{HAuCl}_{4}$ (purple powder). Right: The SEM images of the samples with $\mathrm{HAuCl}_{4}$ /glass after grinding show a few gold nanoparticles in the bulk (bright structures).
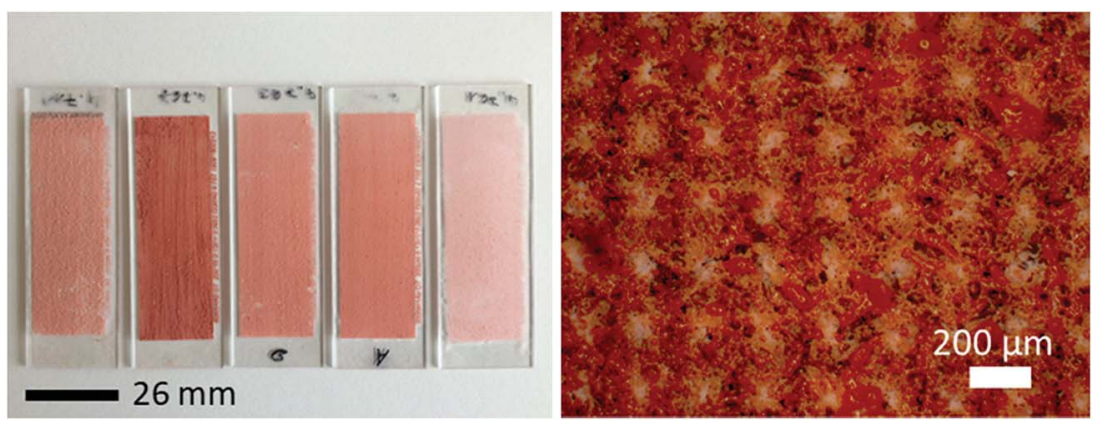

Fig. 2 Gold particles laser sintered on the object slides (left image; from left to right: $\mathrm{HAuCl}_{4}$ with 1-2, 50, 100, 200 and 370 nm porous glass). A light microscopy close up view with $5 \times$ magnification of the coating structure with gold nanoparticles (right image). Here, the course of the laser is visible in the red sintered grids with particles and the white non-sintered spaces containing no particles.

induce catalysis of chosen contaminants. SEM images from the surface of a slide coated with gold (Fig. 3, left) and the fracture plane of such an object slide (Fig. 3, right) show evidence that gold nanoparticles of around $30 \mathrm{~nm}$ in size are present on the surface (visible as bright spherical spots), but are also found melted into the glass or in second order pores of sizes up to 3 $\mu \mathrm{m}$ (which were apparently formed by the melting of the glass during the laser sintering process).

Transmission measurements of the different sample object slides in an Ulbricht-sphere (Fig. 4) revealed a transmission minimum (absorption maximum) of $522 \mathrm{~nm}$ for the gold samples with porous glass of 1-2, 50, 100 and $200 \mathrm{~nm}$, and of 528 for the sample with $370 \mathrm{~nm}$ porous glass. An absorption peak at $522 \mathrm{~nm}$ is typical for $30 \mathrm{~nm}$ gold spheres, and at 528 for particles with a size of $42 \mathrm{~nm} .^{61}$ Thus, the Ulbricht sphere measurements support the size found in the SEM images, but also clarify that the particles must be placed at the glass surface.

Simulations using Mie-theory revealed a red-shift of the absorption band of gold nanoparticles from air $(520 \mathrm{~nm})$ to water $(545 \mathrm{~nm})$ and to the glass environment (565 nm; Fig. 5). When comparing these results with the Ulbricht sphere measurements (absorption maxima at 522 and $528 \mathrm{~nm}$; Fig. 4) and knowing that the approximate size of the particles is around $30 \mathrm{~nm}$, it can be concluded that the obtained particles are located on the surface, exposed to air and therefore able to be activated by light and reachable by contaminant molecules.
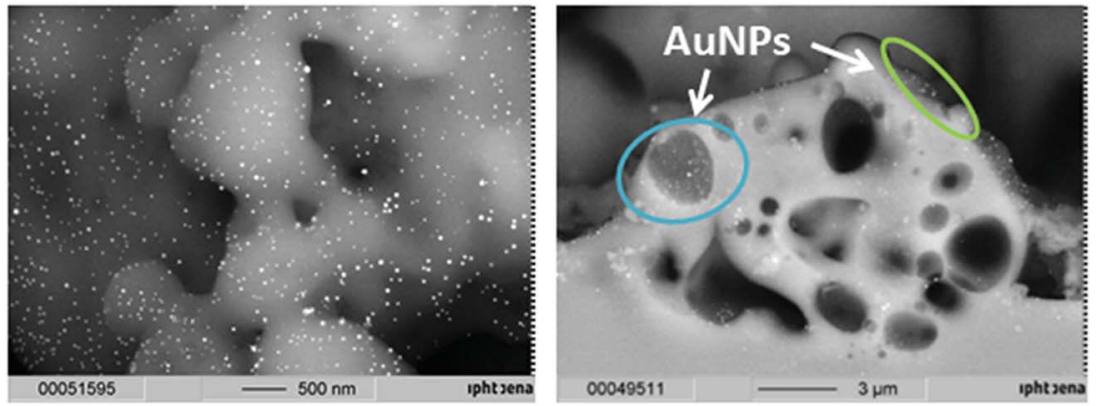

Fig. 3 SEM images of gold nanoparticles on a laser sintered glass substrate (top view, left image) and a fracture plane image of an object slide (right image) with gold nanoparticles in pores (blue circle) and on the surface (green circle). 


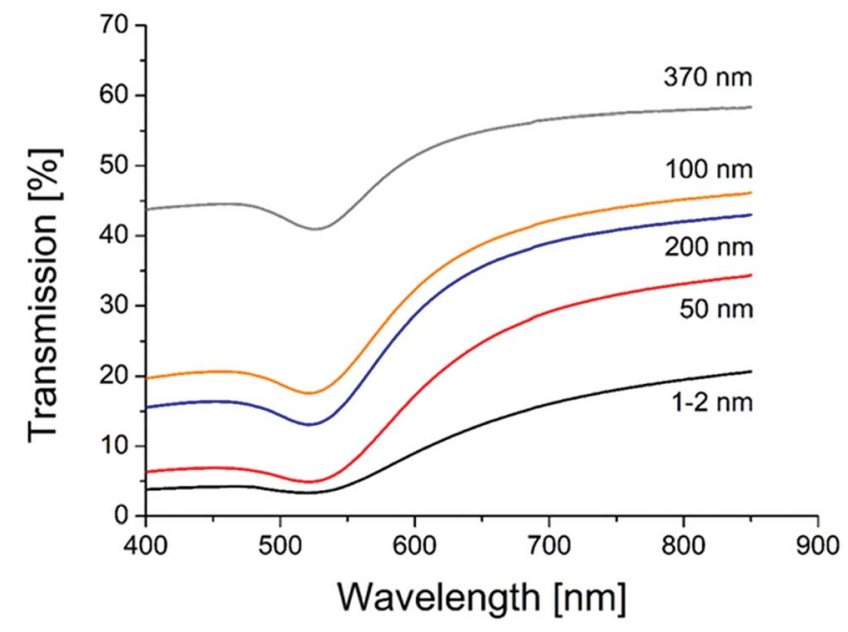

Fig. 4 UV/VIS transmission spectra of AuNP catalysts on different porous glasses (pore sizes are given on each curve).

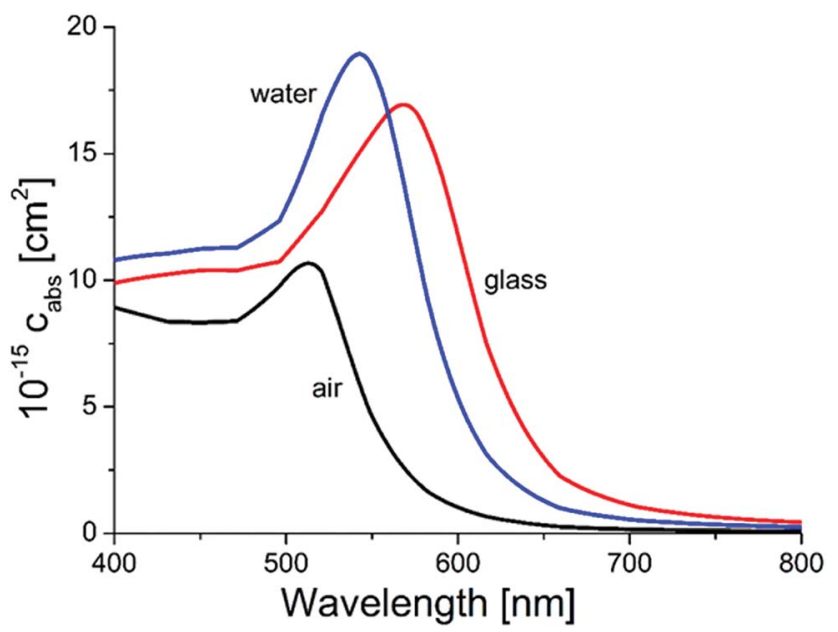

Fig. 5 Results from Mie-calculations for the absorption wavelengths of $80 \mathrm{~nm}$ AuNPs in different surrounding media (air, water and glass).

This is also in good agreement with the literature, where similar shifting effects of gold nanoparticles ( $20 \mathrm{~nm}$ size) embedded in glass could be obtained by calculations. ${ }^{62}$

Besides these UV/VIS measurements using the Ulbricht sphere, XRD was utilized to study the particle size using the Scherrer equation (Fig. 6, Table S3 ESI $\dagger$ ). For the measured sample containing gold particles with $200 \mathrm{~nm}$ porous glass, the positions of the (111), (200), (220) and (311) features of monocrystalline gold nanoparticles are at positions of $2 \Theta=38.2$, 44.4, 64.6 and 77.6, which is consistent with the literature. ${ }^{63,64}$ The calculated crystallite size $L$ resulted in a value of $30 \mathrm{~nm}$ for this sample, supporting the previous results from Ulbrichtsphere measurements and from SEM imaging.

The scaling-up of the production process was demonstrated by coating of carrier plates matching the test reactor. These plates are of a $150 \times 150 \mathrm{~mm}$ size with an area of $100 \times 100 \mathrm{~mm}$ in the center of the plate to be coated with the catalytic active material. The coating process was therefore carried out exactly

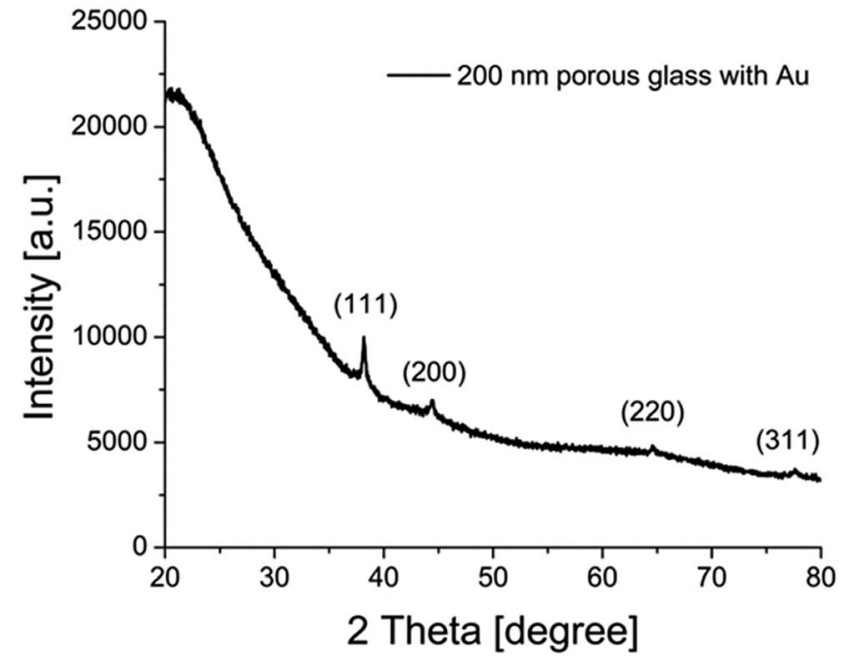

Fig. 6 An XRD diffractogram of AuNPs on a layer of porous (200 nm pore size) glass.

as it was for the object slides with the same glass/metal precursor mixture in the pretests. This should result in reproducible products. Indeed, we could also see a uniform, brightly red coloured coating of gold nanoparticles for such a large area.

In total, six plates with a pure gold coating and two with a bimetallic coating were obtained by this process (Fig. 7). This technique also allows estimation of the amount of metal precursor utilized, and therefore the catalyst mass per plate (Table 1). The plates are denoted regarding the pore size of the glass used in the grinding process.

Besides the scalability of the process, the costs of the precursor for the nanoparticles can also be considered as favorable, as they range from $0.15 €$ in the case of the $200 \mathrm{~nm}$ porous glass plate $\mathrm{B}$ to $0.76 €$ for the $1-2 \mathrm{~nm}$ porous glass with AuNPs. Through adding more metal precursor to the glass/ metal salt mixture, an increase in the number of catalyst particles on the support could be achieved easily, however this consequently results in higher metal salt costs.

\subsection{Application of catalyst system in heterogeneous catalysis}

The obtained catalysts are intended to be used for plasmon driven heterogeneous catalysis for waste gas cleaning by degradation of relevant contaminants. In the following experiments, the catalytic performance of the constantly irradiated catalysts was validated using ethanol as a model contaminant in the gas phase. In order to investigate the catalytic effect of the produced catalyst system, tests were carried out in a selfconstructed laboratory testing plant (Fig. 8).

The model contaminant ethanol was placed in a glass saturator and vaporized at $273 \mathrm{~K}$, and was carried into the testing plant by nitrogen in order to inhibit reactions before passing the catalyst. Therefore, oxidant air is mixed with the nitrogen/ ethanol gas flow shortly before the reactor. The results of the degradation tests with the $200 \mathrm{~nm}$ catalyst plate B are displayed in Fig. 9. 


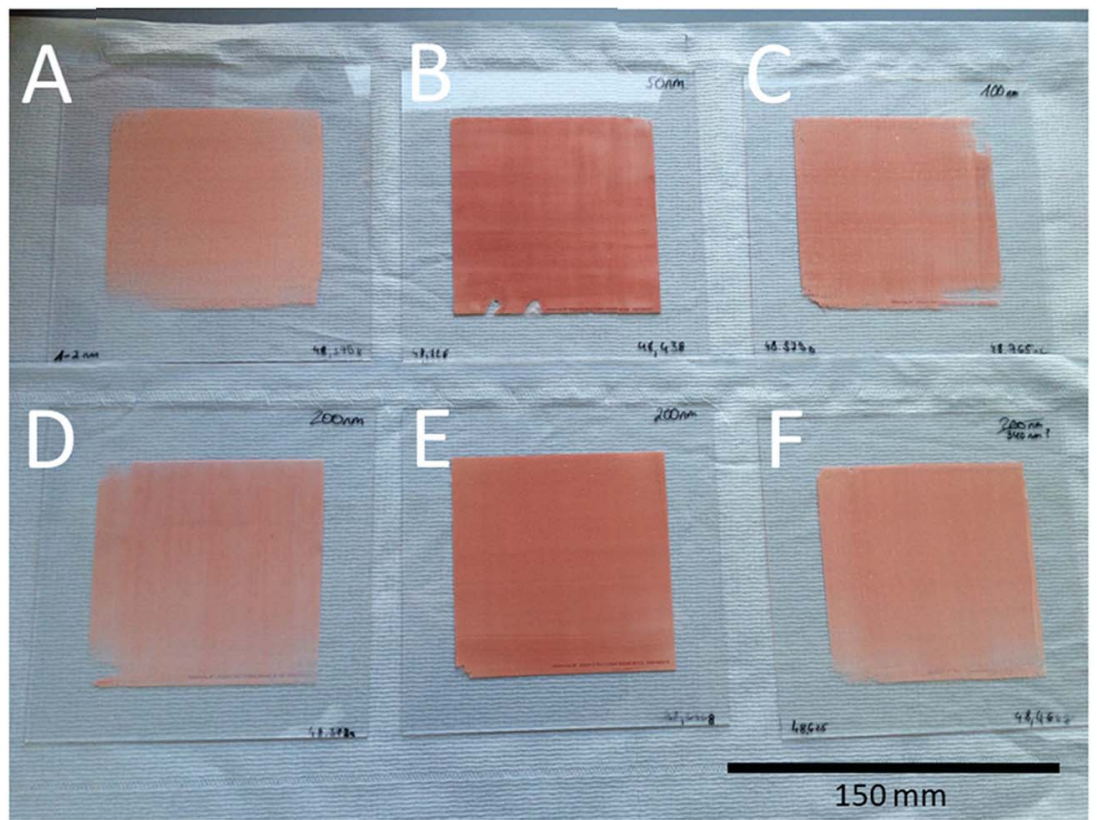

Fig. 7 Catalyst plates with a $150 \times 150 \mathrm{~mm}$ size and a coated area of $100 \times 100 \mathrm{~mm}$ each. $\mathrm{A}=1-2 \mathrm{~nm}, \mathrm{~B}=50 \mathrm{~nm}, \mathrm{C}=100 \mathrm{~nm}, \mathrm{D}=200 \mathrm{~nm}$ plate, $A, E=200 \mathrm{~nm}$ plate and $B, F=370 \mathrm{~nm}$ porous glass.

Table 1 Gold precursor costs referring to the mass of each layer of a $100 \mathrm{~mm}^{2}$ area ( $\mathrm{HAuCl}_{4}$-trihydrate, $49.5 \% \mathrm{Au}, 1 \mathrm{~g}=85.4 €$ at Alfa Aesar, October 2016) and the final gold content in the layer $^{a}$

\begin{tabular}{|c|c|c|c|c|}
\hline $\begin{array}{l}\text { Pore size of } \\
\text { glass [nm] }\end{array}$ & $\begin{array}{l}\text { Amount of glass/metal } \\
\text { precursor per layer }{ }^{b}[\mathrm{mg}]\end{array}$ & $\begin{array}{l}\text { Au content per } \\
\left.\text { layer [as } \mathrm{mg} \mathrm{HAuCl}_{4}\right]\end{array}$ & $\begin{array}{l}\text { Au content in } \\
\text { layer [as mg Au] }\end{array}$ & $\begin{array}{l}\text { Costs of } \mathrm{HAuCl}_{4} \text { per } \\
\text { layer }[€]\end{array}$ \\
\hline $1-2$ & 439 & 8.91 & 4.41 & 0.76 \\
\hline 100 & 214 & 4.02 & 1.99 & 0.34 \\
\hline 200 & $299 / 87$ & $6.07 / 1.76$ & $3.00 / 0.87^{c}$ & $0.52 / 0.15$ \\
\hline 370 & 159 & 3.14 & 1.55 & 0.27 \\
\hline
\end{tabular}

${ }^{a}$ The Au content of the laser-sintered layers relates to the gold content of the glass/metal precursor and its amount used for laser sintering. ${ }^{b}$ Applied amount of the glass/metal precursor for laser sintering. ${ }^{c}$ For the samples with glass of $200 \mathrm{~nm}$ initial porosity, two plates were obtained (displayed in Fig. 7D and E).

The ethanol peak area measured without light is stable, with the exception of a few outliers (Fig. 9 top, crosses in the blue area). The same applies to the peak areas of $\mathrm{CO}_{2}$ coming from the air flow measured by TCD (Fig. 9 top, circles in the blue area). When the light is switched on, a rapid decrease in the ethanol concentration can be seen along with an increase in

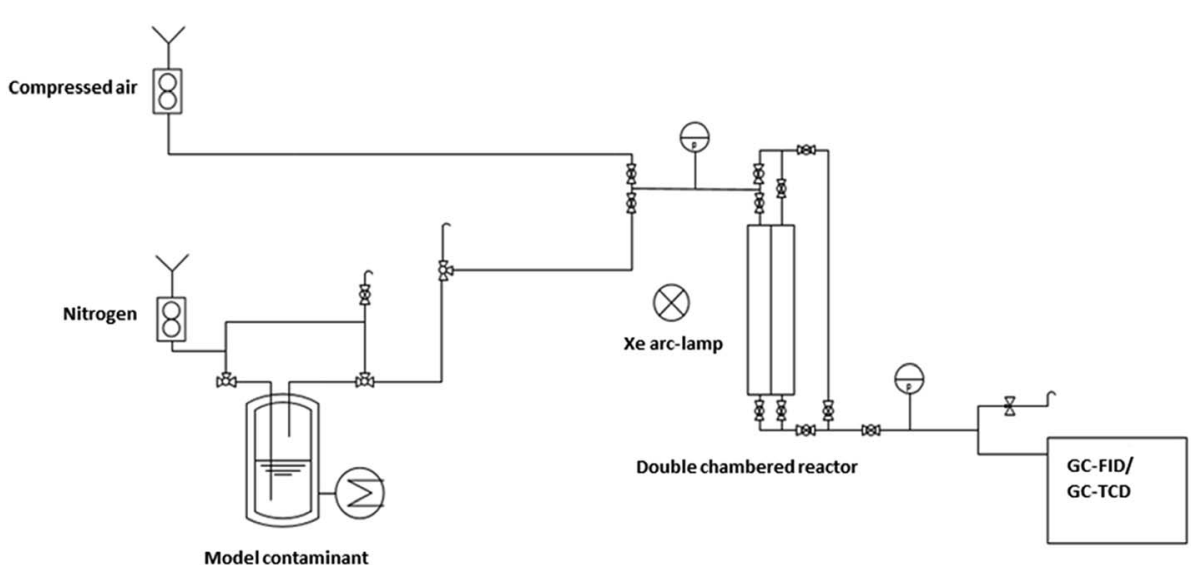

Fig. 8 Setup of the laboratory testing plant. 


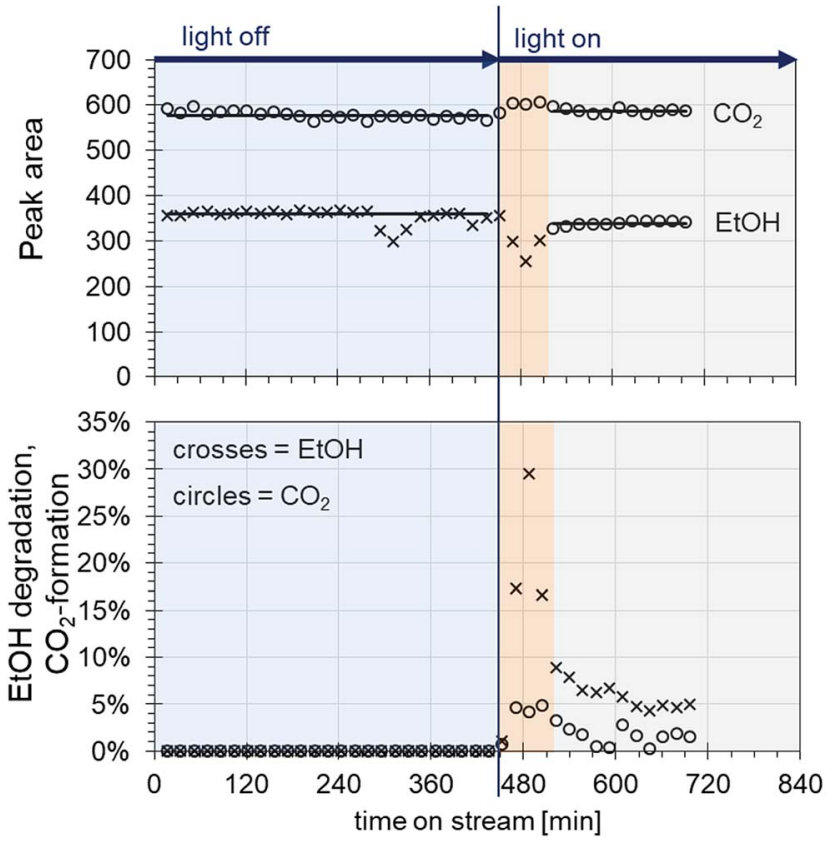

Fig. 9 Result of the degradation tests with ethanol at a flow rate of 30

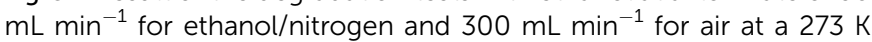
saturator temperature regarding evolution of ethanol/ $\mathrm{CO}_{2}$ peak areas (top) and the percentage of ethanol degradation $/ \mathrm{CO}_{2}$ formation (bottom).

$\mathrm{CO}_{2}$, indicating ethanol degradation (Fig. 9 top, crosses and circles in the red area, and see also Fig. S1 ESI†). However, after around $50 \mathrm{~min}$, the ethanol peak area increases again until it reaches steady state. In parallel, the $\mathrm{CO}_{2}$ peak area decreases, and then reaches a plateau (Fig. 9 top, crosses and circles in the grey area). This behaviour could be due to desorption processes of ethanol from the catalyst. As the conditioning and measurements of the initial ethanol concentration without light are carried out by bypass flow through the reactor with the catalyst inside, a certain amount of ethanol could adsorb onto the catalyst surface. When the light is switched on, only the ethanol arriving in the gas flow is degraded, until the catalyst is heated up to the extent that the adsorbed ethanol is also released. This might happen either through the thermal energy coming from the utilized light source or through plasmon heating. The outer temperature at the reactor window was around $45{ }^{\circ} \mathrm{C}$. Later, the catalyst reaches equilibrium of adsorption/desorption and degradation, and a stable ethanol peak area is measured lying beyond the initial ethanol concentration.

Looking at the degradation of ethanol and the $\mathrm{CO}_{2}$ formation by percent (Fig. 9, bottom), an ethanol degradation of up to $30 \%$ was achieved along with a $\mathrm{CO}_{2}$ increase of around $5 \%$. After reaching equilibrium, the ethanol degradation was at values of around $5 \%$ and the $\mathrm{CO}_{2}$ was around $2 \%$. Along with the degradation rates, it was possible to evaluate the weight hourly space velocity (WHSV) as a catalytic key figure describing the reactor system (Table S4, ESI $†$ ). In our case, the WHSV could be calculated as $5.94 \mathrm{~h}^{-1}$.
Regarding the stability of the catalyst plate, it remained stable during the entire catalytic process for $720 \mathrm{~min}$ and no change of colour, loss of material, or adsorption of contaminants could be detected. Concerning the last point mentioning adsorption of the model contaminant ethanol on the catalyst, Raman studies were carried out with the used catalyst plate before and after catalysis and with ethanol in order to verify its Raman shift (Fig. S2, ESI $\dagger$ ). The measured peak position of ethanol is in good agreement with the literature ${ }^{65,66}$ and it could be confirmed that no ethanol was adsorbed onto the catalyst plate, guaranteeing still accessible gold nanoparticles after the catalytic process.

\section{Conclusion}

In the present studies we could demonstrate an elegant, easy and inexpensive way to design a heterogeneous catalyst system on a glass support with different support sizes. The technique requires only two steps; the production of glass/metal precursor powders in a mixer ball mill, and the laser sintering of this material on the glass support with the desired size. Here, we could show that it is possible to obtain catalysts on supports with sizes of $20 \times 60$ to $100 \times 100 \mathrm{~mm}$ with AuNPs as plasmon catalytic active particles. Through the grinding and laser sintering processes, the porosity of the glasses mixed with the metal precursors is not preserved, but metal nanoparticles were formed. The sizes of these particles were usually around $30 \mathrm{~nm}$. Thus, it seems to be unimportant whether the utilized glass shows any porosity or which size the pores are, so any kind of glass seems applicable. A very important aspect of this to question is if the formed gold nanoparticles are also located on the glass surface. This could be confirmed, which enables the established catalyst systems to be used for catalytic applications.

A key issue regarding the utilization of noble metal catalysts is the costs of such systems, especially for the cost-intensive metal salts used as particle precursors. Calculating the costs of our method, we could obtain prices ranging from a few cents up to $0.76 €$ for $\mathrm{HAuCl}_{4}$ per $100 \mathrm{~cm}^{2}$ catalyst area, which is a rather inexpensive approach.

Finally, catalytic tests analyzing the degradation of ethanol showed that a decrease in ethanol concentration of up to $30 \%$ is possible with the catalyst system displayed. Parallel to the ethanol degradation, $\mathrm{CO}_{2}$ formation could be measured as the resulting degradation product. It turned out, however, that the catalyst requires a certain warm-up time to reach equilibrium of the ethanol adsorption/desorption and degradation, which occurs due to thermal energy input or plasmon heating. This leads to a lowered but stable ethanol degradation of around $5 \%$ and a $\mathrm{CO}_{2}$ formation of $2 \%$.

In conclusion, a novel approach for the fabrication of a heterogeneous plasmon-driven photocatalyst system is introduced, based on the laser-assisted sintering of a mixture of ground glass with a metal salt precursor on a glass substrate. The fabrication process is demonstrated, and the resulting catalyst areas are characterized as well as successfully tested using ethanol degradation as a model reaction. The procedure 
is easily scalable to larger areas and is quite cost-efficient, representing a promising novel approach for heterogeneous photocatalysis.

\section{Conflicts of interest}

There are no conflicts to declare.

\section{Acknowledgements}

This work was carried out within the project \#6 of pades Wachstumskern Thüringen (FKZ 03WKCN06). We thank pades Partikeldesign Thüringen and the BMBF (German Federal Ministry of Education and Research) for funding this project. Also we cordially thank Torsten Langer from JENOPTIK Automatisierungstechnik GmbH (Jena) and Robert Bischoff from HEGLA boraident (Halle/Saale). We would also like to express many thanks to Beate Fähndrich from the Institute of Technical Chemistry and Environmental Chemistry, FriedrichSchiller-University Jena for BET measurements and Andrea Dellith (Leibniz-Institute of Photonic Technology Jena) for SEM imaging, Christa Schmidt (Leibniz-Institute of Photonic Technology Jena) for XRD measurements and Dr Clara Stiebing and Dr Jan Rüger (Leibniz-Institute of Photonic Technology Jena) for Raman measurements. We express our special thanks to the Open Access Fund of the Leibniz Association for the funding of the publication of this article.

\section{References}

1 A. Csáki, M. Thiele, J. Jatschka, A. Dathe, D. Zopf, O. Stranik and W. Fritzsche, Eng. Life Sci., 2015, 15, 266-275.

2 K. A. Willets and R. P. V. Duyne, Annu. Rev. Phys. Chem., 2007, 58, 267-297.

3 S. Szunerits and R. Boukherroub, Chem. Commun., 2012, 48, 8999-9010.

4 A. Campion and P. Kambhampati, Chem. Soc. Rev., 1998, 27, 241-250.

5 K. Kneipp, H. Kneipp, I. Itzkan, R. R. Dasari and M. S. Feld, Chem. Rev., 1999, 99, 2957-2976.

6 P. Christopher, H. Xin and S. Linic, Nat. Chem., 2011, 3, 467472.

7 R. Narayanan and M. A. El-Sayed, J. Phys. Chem. B, 2005, 109, 12663-12676.

8 J. R. Adleman, D. A. Boyd, D. G. Goodwin and D. Psaltis, Nano Lett., 2009, 9, 4417-4423.

9 B. Dong, Y. Fang, X. Chen, H. Xu and M. Sun, Langmuir, 2011, 27, 10677-10682.

10 S. Mukherjee, F. Libisch, N. Large, O. Neumann, L. V. Brown, J. Cheng, J. B. Lassiter, E. A. Carter, P. Nordlander and N. J. Halas, Nano Lett., 2013, 13, 240-247.

11 G. L. Hallett-Tapley, M. J. Silvero, M. González-Béjar, M. Grenier, J. C. Netto-Ferreira and J. C. Scaiano, J. Phys. Chem. C, 2011, 115, 10784-10790.

12 J. Turkevich, P. C. Stevenson and J. Hillier, Discuss. Faraday Soc., 1951, 11, 55-75.

13 G. Frens, Nature (London), Phys. Sci., 1973, 241, 20-22.
14 M. Brust, M. Walker, D. Bethell, D. J. Schiffrin and R. Whyman, J. Chem. Soc., Chem. Commun., 1994, 801-802.

15 N. G. Bastús, J. Comenge and V. Puntes, Langmuir, 2011, 27, 11098-11105.

16 N. R. Jana, L. Gearheart and C. J. Murphy, J. Phys. Chem. B, 2001, 105, 4065-4067.

17 B. Nikoobakht and M. A. El-Sayed, Chem. Mater., 2003, 15, 1957-1962.

18 J. Pérez-Juste, I. Pastoriza-Santos, L. M. Liz-Marzán and P. Mulvaney, Coord. Chem. Rev., 2005, 249, 1870-1901.

19 H.-L. Wu, C.-H. Kuo and M. H. Huang, Langmuir, 2010, 26, 12307-12313.

20 M. Thiele, J. Z. E. Soh, A. Knauer, D. Malsch, O. Stranik, R. Müller, A. Csáki, T. Henkel, J. M. Köhler and W. Fritzsche, Chem. Eng. J., 2016, 288, 432-440.

21 P. S. Kumar, I. Pastoriza-Santos, B. Rodríguez-González, F. J. García de Abajo and L. M. Liz-Marzán, Nanotechnology, 2008, 19, 015606.

22 A. Pyatenko, M. Yamaguchi and M. Suzuki, J. Phys. Chem. C, 2007, 111, 7910-7917.

23 Y. Wan, Z. Guo, X. Jiang, K. Fang, X. Lu, Y. Zhang and N. Gu, J. Colloid Interface Sci., 2013, 394, 263-268.

24 Y. Sun and Y. Xia, Science, 2002, 298, 2176-2179.

25 D. Yu and V. W.-W. Yam, J. Am. Chem. Soc., 2004, 126, 1320013201.

26 I. Pastoriza-Santos and L. M. Liz-Marzán, Nano Lett., 2002, 2, 903-905.

27 D. Aherne, D. M. Ledwith, M. Gara and J. M. Kelly, Adv. Funct. Mater., 2008, 18, 2005-2016.

28 A. Knauer, A. Csáki, F. Möller, C. Hühn, W. Fritzsche and J. M. Köhler, J. Phys. Chem. C, 2012, 116, 9251-9258.

29 T. Teranishi, M. Miyake and M. Hosoe, Adv. Mater., 1997, 9, 65-67.

30 T. S. Ahmadi, Z. L. Wang, A. Henglein and M. A. El-Sayed, Chem. Mater., 1996, 8, 1161-1163.

31 J. Turkevich and G. Kim, Science, 1970, 169, 873-879.

32 T. Teranishi and M. Miyake, Chem. Mater., 1998, 10, 594600.

33 W. Niu, Z.-Y. Li, L. Shi, X. Liu, H. Li, S. Han, J. Chen and G. Xu, Cryst. Growth Des., 2008, 8, 4440-4444.

34 S. Sarina, E. R. Waclawik and H. Zhu, Green Chem., 2013, 15, 1814-1833.

35 S. Linic, P. Christopher and D. B. Ingram, Nat. Mater., 2011, 10, 911-921.

36 C. Burda, X. Chen, R. Narayanan and M. A. El-Sayed, Chem. Rev., 2005, 105, 1025-1102.

37 J. Li, E. Saydanzad and U. Thumm, Phys. Rev. A, 2016, 94, 051401.

38 M. Bernardi, J. Mustafa, J. B. Neaton and S. G. Louie, Nat. Commun., 2015, 6, 7044.

39 M. Gonzalez-Bejar, K. Peters, G. L. Hallett-Tapley, M. Grenier and J. C. Scaiano, Chem. Commun., 2013, 49, 1732-1734.

40 S. Eustis and M. A. El-Sayed, Chem. Soc. Rev., 2006, 35, 209217.

41 T. S. Rodrigues, A. G. M. da Silva, A. B. L. de Moura, I. G. Freitas and P. H. C. Camargo, RSC Adv., 2016, 6, 62286-62290. 
42 H. Wu, P. Wang, H. He and Y. Jin, Nano Res., 2012, 5, 135144.

43 Z. Zheng, T. Tachikawa and T. Majima, J. Am. Chem. Soc., 2015, 137, 948-957.

44 F. Wang, C. Li, H. Chen, R. Jiang, L.-D. Sun, Q. Li, J. Wang, J. C. Yu and C.-H. Yan, J. Am. Chem. Soc., 2013, 135, 55885601.

45 X. Huang, Y. Li, Y. Chen, H. Zhou, X. Duan and Y. Huang, Angew. Chem., 2013, 125, 6179-6183.

46 P. Wang, B. Huang, Y. Dai and M.-H. Whangbo, Phys. Chem. Chem. Phys., 2012, 14, 9813-9825.

47 Z. Zheng, T. Tachikawa and T. Majima, J. Am. Chem. Soc., 2014, 136, 6870-6873.

48 C. Wang and D. Astruc, Chem. Soc. Rev., 2014, 43, 7188-7216.

49 S. A. Ansari, M. M. Khan, M. O. Ansari and M. H. Cho, New J. Chem., 2015, 39, 4708-4715.

50 N. Pugazhenthiran, S. Murugesan, P. Sathishkumar and S. Anandan, Chem. Eng. J., 2014, 241, 401-409.

51 F. Kim, J. H. Song and P. Yang, J. Am. Chem. Soc., 2002, 124, 14316-14317.

52 Y.-Y. Yu, S.-S. Chang, C.-L. Lee and C. R. C. Wang, J. Phys. Chem. B, 1997, 101, 6661-6664.

53 V. Amendola, S. Polizzi and M. Meneghetti, J. Phys. Chem. B, 2006, 110, 7232-7237.

54 J. Zhang, D. N. Oko, S. Garbarino, R. Imbeault, M. Chaker, A. C. Tavares, D. Guay and D. Ma, J. Phys. Chem. C, 2012, 116, 13413-13420.
55 R. Intartaglia, G. Das, K. Bagga, A. Gopalakrishnan, A. Genovese, M. Povia, E. Di Fabrizio, R. Cingolani, A. Diaspro and F. Brandi, Phys. Chem. Chem. Phys., 2013, 15, 3075-3082.

56 J. Zhang, M. Chaker and D. Ma, J. Colloid Interface Sci., 2017, 489, 138-149.

57 S. Mukherjee, L. Zhou, A. M. Goodman, N. Large, C. AyalaOrozco, Y. Zhang, P. Nordlander and N. J. Halas, J. Am. Chem. Soc., 2014, 136, 64-67.

58 E. Rombi, M. G. Cutrufello, R. Monaci, C. Cannas, D. Gazzoli, B. Onida, M. Pavani and I. Ferino, J. Mol. Catal. A: Chem., 2015, 404-405, 83-91.

59 W. Hou, W. H. Hung, P. Pavaskar, A. Goeppert, M. Aykol and S. B. Cronin, ACS Catal., 2011, 1, 929-936.

60 T. Nakamura, J. Mater. Res., 2008, 23, 968-974.

61 W. Haiss, N. T. Thanh, J. Aveyard and D. G. Fernig, Anal. Chem., 2007, 79, 4215-4221.

62 V. A. G. Rivera, F. A. Ferri and E. Marega Jr, in Plasmonics Principles and Applications, ed. K. Y. Kim, InTech, Rijeka, 2012, ch. 11, DOI: 10.5772/50753.

63 S. Krishnamurthy, A. Esterle, N. C. Sharma and S. V. Sahi, Nanoscale Res. Lett., 2014, 9, 627.

64 M. M. H. Khalil, E. H. Ismail and F. El-Magdoub, Arabian J. Chem., 2012, 5, 431-437.

65 B. N. Khlebtsov, Z. Liu, J. Ye and N. G. Khlebtsov, J. Quant. Spectrosc. Radiat. Transfer, 2015, 167, 64-75.

66 Q. Wang, Z. Li, Z. Ma and L. Liang, Sens. Actuators, B, 2014, 202, 426-432. 